\title{
PRODUTIVIDADE DO Panicum maximum cv. Mombaça IRRIGADO, SOB PASTEJO ROTACIONADO'
}

\author{
Marcela dos Santos Müller 2,3 ; Antonio Luiz Fancelli2; Durval Dourado-Neto ${ }^{2,3 *}$; Axel García y \\ García $^{2,3}$; Ramiro Fernando López Ovejero 2,4 \\ ${ }_{3}^{2}$ Depto. de Produção Vegetal - USP/ESALQ, C.P. 9 - CEP: 13418-900 - Piracicaba, SP. \\ ${ }^{3}$ Bolsista CNPq. \\ ${ }^{4}$ Bolsista CAPES. \\ *Autor correspondente <dourado@esalq.usp.br>
}

RESUMO: O uso da irrigação em pastagens é uma realidade fundamentada na experiência empírica de produtores, devido à falta de bases científicas definidas sobre o assunto. $O$ trabalho visou avaliar a produtividade do capim Mombaça (Panicum maximum Jacq. cv. Mombaça) manejado em pastejo rotacionado, sob sistema de irrigação e as principais variáveis climáticas responsáveis pelo acúmulo de massa de forragem. O experimento foi conduzido sob irrigação por aspersão tipo pivô central, de julho a dezembro de 1998, em região de cerrado (Latossolo Vermelho-Amarelo) em São Desidério, BA. Foi quantificada a massa de forragem da pastagem aos 30 dias de crescimento e antes do pastejo e desenvolvidos modelos matemáticos que relacionam a produção de forragem a variáveis climáticas. A produção e a taxa de acúmulo de matéria seca da pastagem, ao longo do período de inverno não apresentaram diferenças significativas. Na primavera, houve tendência de aumento em ambas, com maiores produções obtidas no período final de avaliação. As menores taxas de acúmulo durante a primavera foram observadas nos primeiros piquetes, coincidindo com a ocorrência de baixas temperaturas durante o período de descanso. Com a elevação da temperatura mínima, a produção forrageira entrou em fase de acúmulo crescente. A produção de forragem, durante a primavera, foi superior à do inverno, apresentando incrementos em função da maior temperatura mínima do ar, do período de descanso e da área foliar inicial. As principais variáveis climáticas responsáveis pela produção da forragem foram temperatura mínima do ar e disponibilidade de água no solo.

Palavras-chave: pastagem, irrigação, Mombaça, modelagem

\section{PRODUCTIVITY OF Panicum maximum cv. Mombaça UNDER ROTATIONAL GRAZING AND IRRIGATION}

\begin{abstract}
Irrigation of tropical grasses is a reality based on the empirical knowledge of farmers, having no scientific evidence. This field experiment was carried out to evaluate the productivity of the Mombaça grass (Panicum maximum Jacq.cv. Mombaça) under rotational grazing and center pivot irrigation, and the main weather attributes responsible for increases of the Mombaça dry mass yield. The experiment was carried out from July to December 1998, in the Central Brazilian Savannah region (Typic Haplustox), São Desidério, Bahia, Brazil. The Mombaça forage mass was measured at 30 days of growth and before each grazing. Mathematical models were developed to relate the forage productivity to weather attributes. The dry mass yield and the rate of growth, during the winter season, were not statistically different. Even though, both of them increased during the spring season, with the higher dry mass yield at the end of the experimental evaluation period. The lower growth rates, during the spring season, were observed in the initial period, corresponding to lower air temperatures during the pasture rest period. With the increase of the minimum air temperature, the dry mass yield also increased. The forage yield was higher during the spring season as compared to the winter season, because of the higher minimum air temperature during the rest period, and of the initial leaf area. At the Savannah region, the main attributes responsible for increasing the Mombaça dry mass yield were minimum air temperature and soil water availability.
\end{abstract}

Key words: pasture, irrigation, Mombaça, modeling

\section{INTRODUÇÃO}

A literatura concernente ao desempenho agronômico de pastagens irrigadas ainda é restrita e, na maioria dos casos, datada de décadas atrás. Porém, o uso da irrigação de pastagens na região do Cerrado é uma realidade fundamentada na experiência empírica de produtores e que ainda não encontra alicerces na pesquisa acadêmica. A agricultura, nessa região, utiliza tecnologia avançada e a irrigação mostra-se fundamental no processo produtivo. Contudo, os baixos rendimentos alcançados nessas áreas, em função da disseminação de pragas e doenças, aliados à realidade agrícola nacional, forçaram os produtores a medidas extremas e até então inéditas, como a introdução das pastagens nas áreas irrigadas.

${ }^{1}$ Parte da Dissertação de Mestrado da primeira autora apresentada à USP/ESALQ - Piracicaba, SP. 
O capim Mombaça, foi lançado no Brasil em 1993, pela EMBRAPA, no Centro Nacional de Pesquisa de Gado de Corte (Jank et al., 1994; Jank, 1995). É um cultivar de alta produtividade, apresenta elevada porcentagem de folhas, principalmente na seca, destacando-se também por apresentar menor estacionalidade de produção do que o cultivar Colonião.

É íntima relação entre os fatores ambientais e a ocorrência e distribuição das plantas forrageiras, mostrando a necessidade de se conhecer a disponibilidade desses fatores e as características ecológicas e fenológicas das plantas a serem cultivadas (Silva, 1995). Apesar da dificuldade de se isolarem os efeitos de uma variável meteorológica sobre a produção de cultura, os fatores climáticos são os mais importantes na escolha de plantas forrageiras para uma determinada região (Alcântara \& Bufarah, 1985), sendo a umidade e a temperatura fatores preponderantes na distribuição geográfica da tribo Paniceae (Silva, 1995). Sob condições de temperaturas médias anuais iguais ou superiores a $29^{\circ} \mathrm{C}$ e de inverno acima de $15^{\circ} \mathrm{C}$, o fator temperatura perde importância e as condições hídricas assumem papel preponderante na fenologia das plantas (Burkart, 1975). A região tropical apresenta temperaturas entre $25^{\circ} \mathrm{C}$ e $30^{\circ} \mathrm{C}$ e pequena variação na radiação incidente (Cooper, 1970). Dessa forma, o período de inverno, em virtude da deficiência hídrica, pode se apresentar como fator limitante ao cultivo agrícola. Entretanto, em regiões cujas temperaturas médias anuais são de $10^{\circ} \mathrm{C}$ a $20^{\circ} \mathrm{C}$ e de inverno entre $5^{\circ} \mathrm{C}$ e $15^{\circ} \mathrm{C}$, a temperatura exerce papel tão importante quanto a umidade na ocorrência e distribuição das plantas (Burkart, 1975).

A taxa de acúmulo de matéria seca em gramíneas tropicais e subtropicais é extremamente baixa sob temperaturas inferiores a $15^{\circ} \mathrm{C}$ (Cooper \& Tainton, 1968; McWilliam, 1978; Gomide, 1994) e entre $5,5^{\circ} \mathrm{C}$ e $14^{\circ} \mathrm{C}$ (Skerman \& Riveros, 1992). Esses autores citaram que a temperatura ótima para o crescimento de P. maximum está entre $19,1^{\circ} \mathrm{C}$ e $22,9^{\circ} \mathrm{C}$. Os efeitos da temperatura mínima sobre o potencial produtivo de capim Pangola (Digitaria decumbens) foram pesquisados por McCloud (1963), observando que a diminuição da temperatura noturna de $30^{\circ} \mathrm{C}$ para $20^{\circ} \mathrm{C}$ e posteriormente para $10^{\circ} \mathrm{C}$, causou redução da produção de matéria seca dessa forrageira em $25 \%$ e $44,5 \%$, respectivamente. A manutenção da temperatura em $10^{\circ} \mathrm{C}$ proporcionou produção relativa de $21 \%$ daquela obtida a $30^{\circ} \mathrm{C}$.

A luminosidade é outro fator de influência sobre os diversos processos metabólicos das plantas, particularmente sobre a fotossíntese. Normalmente, os ambientes tropicais e subtropicais são caracterizados por elevados índices de radiação (acima de 300 cal $\mathrm{cm}^{-2} \mathrm{dia}^{-1}$ ), não constituindo fator limitante ao crescimento de Panicum (Rolim, 1980; Alcântara \&
Bufarah, 1985). Seu padrão de ocorrência e disponibilidade todavia tem influência marcante sobre a distribuição e/ou estacionalidade de produção forrageira. A estacionalidade da produção forrageira é um fenômeno que ocorre na maioria das espécies tropicais, sendo determinado em maior grau pelas limitações climáticas e exaustão energética das plantas após o estádio reprodutivo. (Maldonado et al. 1997). Em ambiente de Cerrado, Pereira et al. (1966) avaliaram o desempenho de dez gramíneas para capineiras, concluindo que a irrigação efetuada no inverno produziu aumento de produção de matéria seca correspondente a $70 \%$ sobre a testemunha.

Com o objetivo de avaliar a capacidade produtiva de P. maximum, Pedreira (1979) promoveu cortes da forragem durante o verão (outubro a março) e no inverno (abril a setembro). $O$ autor observou que a curva de crescimento da cultura apresentou a mesma tendência da curva de distribuição de chuvas. Maldonado et al. (1997), em experimento conduzido no Estado do Rio de Janeiro, observaram que a produção de matéria seca do capim Elefante (Pennisetum purpureum Schum.) respondeu de forma linear à lâmina de água aplicada, ainda que no período de inverno, que se apresenta com deficiência hídrica, todavia, com temperatura e luminosidade adequados à produção de plantas tropicais.

A expressão do potencial genético da planta forrageira é dependente da atuação de componentes imponderáveis, juntamente com todo o sistema de produção adotado. Dessa forma, é necessária a avaliação das relações entre os elementos bióticos e abióticos, em cada sistema, para o melhor estabelecimento de bases de manejo que culminem em rendimentos agrícolas favoráveis. $\mathrm{O}$ trabalho foi realizado com o objetivo de se obter maiores subsídios e parâmetros para a definição da viabilidade técnica da irrigação de poáceas tropicais na região do cerrado, avaliando-se o desempenho da pastagem de capim Mombaça.

\section{MATERIAL E MÉTODOS}

O trabalho foi conduzido em São Desidério, BA, na Fazenda Rio Brilhante $\left(12^{\circ} 55^{\prime} 12^{\prime \prime}\right.$ Sul, $45^{\circ} 42^{\prime} 54^{\prime \prime}$ Oeste e altitude de $750 \mathrm{~m}$ ). O solo da área é classificado como Latossolo Vermelho-Amarelo distrófico.

Com base nos resultados da análise química do solo, procedeu-se sua correção, visando a elevação da saturação por bases para $60 \%$, conforme indicado por Werner (1994). A semeadura foi realizada entre $14 \mathrm{e}$ 17 de janeiro de 1998, em linhas espaçadas de 0,45 $\mathrm{m}$, com distribuição de $15 \mathrm{~kg} \mathrm{ha}^{-1}$ de sementes $(20 \%$ de valor cultural) e $150 \mathrm{~kg} \mathrm{ha}^{-1}$ de superfosfato simples. A emergência das plântulas ocorreu entre 8 e 10 dias após a semeadura. A partir de 90 dias após a semeadura (abril/maio de 1998), a pastagem foi 
submetida ao corte de uniformização com colheita da forragem para ensilagem. Posteriormente, a área foi subdividida radialmente em 18 piquetes de 5,5 ha e acesso a uma aguada central de 1 ha.

O período de pastejo, em cada piquete, foi inicialmente programado para três dias, porém, variou de dois a seis dias em função da massa de forragem apresentada a cada ciclo de pastejo. O manejo da pastagem consistiu na introdução de todo o rebanho no primeiro piquete e sua permanência até o rebaixamento da pastagem, quando o lote era transferido para o piquete seguinte. Em função da semeadura ter sido realizada na estação das águas, foi necessária a irrigação apenas nos períodos de veranico e a partir do final das chuvas (Figura 1). A irrigação consistiu na aplicação de lâmina fixa de $30 \mathrm{~mm}$ semanais.

A adubação de cobertura foi realizada via água de irrigação, imediatamente após o pastejo de cada piquete, com $30 \mathrm{~kg} \mathrm{ha}^{-1}$ de $\mathrm{N} \mathrm{e} \mathrm{K}_{2} \mathrm{O}$, cujas fontes, foram, respectivamente, uréia e cloreto de potássio. O manejo da irrigação foi estabelecido de forma que cada piquete não fosse irrigado imediatamente antes da sua ocupação por animais.

Os dados de produção de forragem foram obtidos através da coleta de amostras em cada um dos piquetes, em duas épocas distintas: imediatamente antes do pastejo (18 observações durante o inverno e 27 na primavera) (Tabela 1), e 30 dias após a retirada dos animais da pastagem (total de 45 observações) (Figura 5). As amostras foram retiradas em cinco pontos aleatórios dentro de cada piquete, delimitadas por um quadro de $1 \mathrm{~m}^{2}$ e corte realizado ao nível do solo. Foi obtida a massa total das amostras, sem subdividi-las em suas partes vegetativas. Para determinação da forragem remanescente após a saída dos animais dos piquetes, o mesmo procedimento de amostragem foi executado.

A taxa média de acúmulo de forragem foi obtida através da relação entre a variação da massa de forragem em cada piquete e o respectivo intervalo entre pastejos (Tabela 1). No primeiro ciclo de pastejo (período de pastejo + período de descanso) (19/07 a

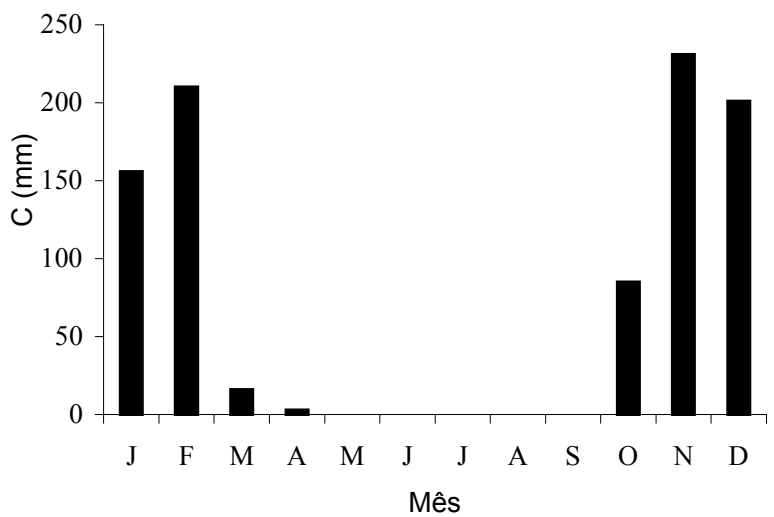

Figura 1 - Precipitação (C) no período de janeiro a dezembro de 1998.
16/09/98), foi considerado o acúmulo total da forragem, visto que toda a pastagem foi submetida, inicialmente, ao corte de uniformização. A partir do segundo ciclo iniciado em 16/09/98, estimou-se que a massa remanescente da forragem foi $27,5 \%$ da observada no momento do início do pastejo. Essa estimativa foi feita através de amostragens efetuadas em cada piquete após a saída dos animais.

Durante a condução do experimento foram monitoradas, diariamente, as temperaturas mínima, máxima, média relativa, pluviosidade e radiação solar, através de uma estação meteorológica local Li-1200 (Licor, Inc. Lincoln, Nebraska, USA), (Figura 2).

\section{RESULTADOS E DISCUSSÃO}

O primeiro ciclo de pastejo efetuado durante o inverno (19/07 a 16/09/98) foi realizado após um período de descanso médio de 88 dias (Tabela 1). 0 longo período de descanso adotado para o início do primeiro ciclo de pastejo deve-se ao tempo demandado para a recuperação das plantas, que pode ser explicado por dois fatores: (i) baixo vigor da rebrota da pastagem em função das condições climáticas vigentes após o corte de uniformização, e (ii) pela rebrota dependente da emissão de perfilhos basais, devido à desfolha excessiva no corte de uniformização das plantas, que provocou a remoção dos meristemas apicais. Essa eliminação deu-se devido ao corte de uniformização ter sido promovido no estádio reprodutivo da planta forrageira, momento em que há o alongamento das hastes com conseqüente elevação dos meristemas.

A rebrota dependente de perfilhos basais ocorre de forma lenta pois depende diretamente das reservas orgânicas da planta para o seu desenvolvimento. Nas forrageiras do gênero Panicum, os perfilhos basais devem ser preferencialmente explorados para obtenção de altos rendimentos e elevada taxa de lotação (Santos, 1993), pois esses contribuem com maior peso de massa verde e de maneira mais vigorosa em relação aos aéreos (Barbosa et al.,1996).

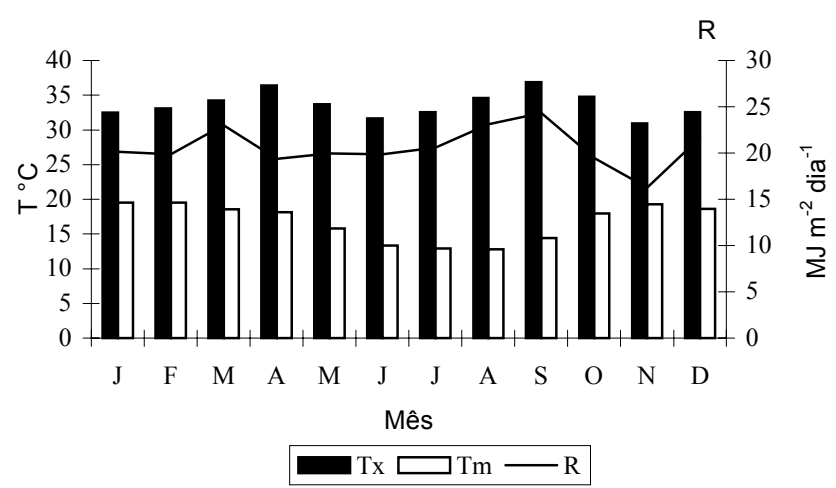

Figura 2 - Temperaturas Médias Máxima (Tx) e Mínima (Tm) e Radiação Solar ( $\mathrm{R}, \mathrm{MJ} \mathrm{m}^{-2}$ dia $\left.^{-1}\right)$ de janeiro a dezembro de 1998. 
Tabela 1 - Massa de forragem do Panicum maximum cv. Mombaça em função da data de coleta e período de descanso (PD).

\begin{tabular}{|c|c|c|c|}
\hline $\begin{array}{l}\text { Data da } \\
\text { coleta }\end{array}$ & Piquete & PD & MS \\
\hline \multicolumn{4}{|c|}{ Inverno } \\
\hline & & dias & $\mathrm{kg} \mathrm{ha}^{-1}$ \\
\hline $19 / 07 / 98$ & 1 & 76 & 3732,7 \\
\hline $25 / 07 / 98$ & 2 & 79 & 3793,6 \\
\hline $30 / 07 / 98$ & 3 & 81 & 3853,7 \\
\hline $04 / 08 / 98$ & 4 & 84 & 3827,9 \\
\hline 07/08/98 & 5 & 84 & 3748,4 \\
\hline $10 / 08 / 98$ & 6 & 85 & 3808,0 \\
\hline $13 / 08 / 98$ & 7 & 87 & 4129,4 \\
\hline $16 / 08 / 98$ & 8 & 88 & 4018,7 \\
\hline $19 / 08 / 98$ & 9 & 89 & 3904,2 \\
\hline $22 / 08 / 98$ & 10 & 91 & 3850,5 \\
\hline $24 / 08 / 98$ & 11 & 91 & 3963,6 \\
\hline $27 / 08 / 98$ & 12 & 91 & 3850,5 \\
\hline $31 / 08 / 98$ & 13 & 92 & 4191,5 \\
\hline 04/09/98 & 14 & 94 & 3991,4 \\
\hline 07/09/98 & 15 & 95 & 4157,6 \\
\hline $10 / 09 / 98$ & 16 & 95 & 4022,0 \\
\hline $12 / 09 / 98$ & 17 & 95 & 4249,4 \\
\hline $14 / 09 / 98$ & 18 & 95 & 4192,8 \\
\hline \multicolumn{4}{|c|}{ Primavera } \\
\hline$\overline{16 / 09 / 98}$ & 1 & 53 & 4220,1 \\
\hline $18 / 09 / 98$ & 2 & 50 & 4035,5 \\
\hline $21 / 09 / 98$ & 3 & 48 & 4283,4 \\
\hline $23 / 09 / 98$ & 4 & 47 & 3886,2 \\
\hline $25 / 09 / 98$ & 5 & 46 & 4307,0 \\
\hline $27 / 09 / 98$ & 6 & 45 & 4009,0 \\
\hline 29/09/98 & 7 & 44 & 3963,2 \\
\hline $01 / 10 / 98$ & 8 & 43 & 5239,0 \\
\hline 03/10/98 & 9 & 42 & 5508,1 \\
\hline $05 / 10 / 98$ & 10 & 42 & 4287,5 \\
\hline 06/10/98 & 11 & 40 & 4900,2 \\
\hline $10 / 10 / 98$ & 12 & 40 & 4590,0 \\
\hline $12 / 10 / 98$ & 13 & 38 & 4032,6 \\
\hline $15 / 10 / 98$ & 14 & 38 & 4836,6 \\
\hline $17 / 10 / 98$ & 15 & 38 & 5788,0 \\
\hline $19 / 10 / 98$ & 16 & 38 & 4564,7 \\
\hline $21 / 10 / 98$ & 17 & 38 & 6015,0 \\
\hline 23/10/98 & 18 & 38 & 4614,1 \\
\hline $25 / 10 / 98$ & 1 & 38 & 6513,1 \\
\hline 27/10/98 & 2 & 36 & 5926,2 \\
\hline 29/10/98 & 3 & 36 & 4637,5 \\
\hline $31 / 10 / 98$ & 4 & 36 & 4987,6 \\
\hline $02 / 11 / 98$ & 5 & 36 & 5204,7 \\
\hline $04 / 11 / 98$ & 6 & 36 & 6160,9 \\
\hline $06 / 11 / 98$ & 7 & 36 & 5856,6 \\
\hline $08 / 11 / 98$ & 8 & 36 & 5913,6 \\
\hline $10 / 11 / 98$ & 9 & 36 & 5595,8 \\
\hline
\end{tabular}

A influência das condições climáticas e do tipo de rebrota sobre o desenvolvimento e produção do cultivar Mombaça é constatada através dos níveis de produção de matéria seca obtidos sob diferentes períodos de descanso, os quais variaram de 36 a 95 dias, na primavera e no inverno, respectivamente, com coeficiente de variação de $20,6 \%$.
A menor massa de forragem no pré-pastejo foi de $3733 \mathrm{~kg} \mathrm{ha}^{-1}$, com período de descanso de 76 dias, em 19/07/98 (Tabela 1), superior aos $1200 \mathrm{~kg} \mathrm{ha}^{-1}$, considerado por Mott (1980), como o mínimo aceitável para o consumo de bovinos em pastejo.

A comparação de médias, pelo teste de Tukey, para a variável massa média de matéria seca, independentemente dos períodos de descanso praticados, mostra que o efeito do período do ano (inverno e primavera) foi altamente significativo (Tabela 2).

O acúmulo médio obtido na primavera (MS, 4958 $\mathrm{kg} \mathrm{ha}^{-1}$ ), com período de descanso médio de 40 dias, superou em $25 \%$ aquele obtido, durante o inverno, em 88 dias (3960 kg ha-1 de MS), demonstrando que a menor freqüência de pastejos, no período de inverno, não promoveu o mesmo acúmulo obtido na primavera. O primeiro dia de avaliação e entrada dos animais no sistema foi considerado como zero, em todos os modelos propostos. Durante o inverno ocorreu o primeiro ciclo de pastejo (18 piquetes), de 19/07/98 a 16/09/98. Na estação de primavera, o pastejo teve início em 16/09/98 e término em 12/11/98, com 27 piquetes pastejados (Tabela 3).

O aumento na produção durante a primavera (Figura 3) foi crescente, com as maiores massas obtidas no período final de avaliação, ainda que essas áreas estivessem sob menores intervalos entre pastejos (36 dias). Acredita-se que esse desempenho seja função da alteração paulatina das condições hídricas e térmicas.

O modelo que melhor explicou a variação da massa de forragem produzida durante a primavera está representado na Tabela 3 (Modelo 1).

No presente estudo, o período de primavera não foi avaliado até o seu término e, considerando-se que nesse período a pastagem foi submetida a maior freqüência de pastejos, depreende-se que as produções de matéria seca teriam sido maiores se os intervalos entre pastejos fossem maiores; concordando com observações de Gomide \& Zago (1981) em estudo da produção do capim Colonião submetido a intervalos de corte.

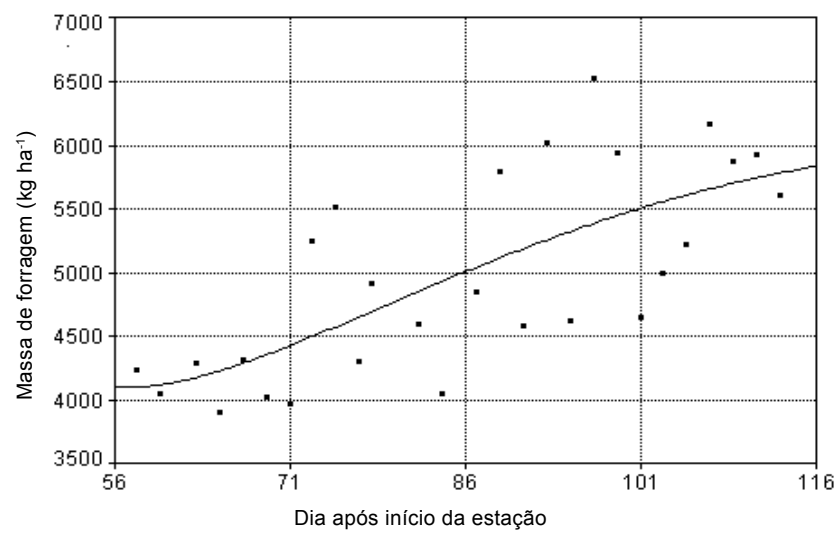

Figura 3 - Massa de forragem do Panicum maximum cv. Mombaça durante a primavera, com período de descanso médio de 40 dias, ao longo das avaliações temporais (Modelo 1). 
Tabela 2 - Análise de variância relativa à taxa de acúmulo $\left(\mathrm{kg} \mathrm{ha}^{-1} \mathrm{dia}^{-1}\right)$ ao longo da avaliações, durante a primavera, massa de matéria seca $\left(\mathrm{kg} \mathrm{ha}^{-1}\right)$ aos 30 dias de descanso, durante as avaliações de inverno e primavera e comparação de médias (MSm, $\mathrm{kg} \mathrm{ha}^{-1}$ ) e total (MSt, $\mathrm{kg}$ ) em função da estação do ano, nos períodos médios de descanso (PD) do Panicum maximum, cv. Mombaça.

\begin{tabular}{|c|c|c|c|c|}
\hline \multicolumn{5}{|c|}{ Taxa de acúmulo } \\
\hline Causa da variação & G.L. & S.Q. & Q.M. & $\mathrm{F}$ \\
\hline Época de amostragem & 26 & 90593,54 & 3484,36 & $7,2058^{\star *}$ \\
\hline Resíduo & 108 & 52223,53 & 483,55 & \\
\hline Total & 134 & & & \\
\hline \multicolumn{5}{|c|}{ Massa de forragem } \\
\hline Época do ano & 44 & 318361468,51 & 7235487,92 & $13,6367^{* *}$ \\
\hline Resíduo & 180 & 95505735,59 & 530587,42 & \\
\hline Total & 224 & & & \\
\hline \multicolumn{5}{|c|}{ Massa de forragem média } \\
\hline Estação & PD & $\mathrm{MSm}^{1}$ & $\mathrm{MSt}^{2}$ & Piquetes Pastejados \\
\hline Inverno & 88 & $3960,33 \mathrm{a}$ & $392.072,67$ & 18 (99 ha) \\
\hline Primavera & 40 & $4958,37 b$ & $736.317,95$ & 27 (148,5 ha) \\
\hline Período total & & 4559,15 & $1.128 .390,62$ & \\
\hline
\end{tabular}

** Significativo a $1 \%$.

Taxa de acúmulo: $\mathrm{CV}=27,2 \% ; \mathrm{s}=26,4 \mathrm{~kg} \mathrm{ha}^{-1} \mathrm{dia}^{-1} ;$ média $=97,0 \mathrm{~kg} \mathrm{ha}^{-1} \mathrm{dia}^{-1}$.

Massa de forragem: CV=29,8\%; $=1206,9 \mathrm{~kg} \mathrm{ha}^{-1} ;$ média $=4045,2 \mathrm{~kg} \mathrm{ha}^{-1}$.

Massa de forragem média: ${ }^{1}$ Médias seguidas pela mesma letra não apresentam diferença pelo teste de Tukey $(\alpha=0,01)$; dms $=250,7$ $\mathrm{kg} \mathrm{ha}^{-1} .^{2}$ Massa referente a todos os piquetes.

A análise de variância referente à taxa de acúmulo de forragem durante a primavera foi altamente significativa $(P<0,01)$ (Tabela 2), devido a alterações nas condições climáticas nesse período. No inverno, a taxa de acúmulo não apresentou diferença. O coeficiente de variação foi de $17,1 \%$ e a média de $44,9 \mathrm{~kg} \mathrm{ha}^{-1} \mathrm{dia}^{-1}$.

A análise de regressão permitiu a obtenção do modelo explanatório que demonstra a tendência da taxa média de acúmulo da pastagem durante o período de primavera (Figura 4). Foi utilizado o software TableCurve 2D (Jandel Scientific, 1994) para ajustar os modelos aos dados observados, minimizando a soma dos quadrados dos desvios, utilizando o procedimento iterativo de Newton-Raphson.

O Modelo 2 (Tabela 3) representou a melhor tendência da taxa de acúmulo do capim Mombaça durante a primavera. As menores taxas de acúmulo durante a primavera ocorreram nos primeiros piquetes pastejados (Figura 4) e coincidem com a ocorrência das menores temperaturas mínimas $\left(13^{\circ} \mathrm{C}\right)$ durante 0 período de descanso. A partir da elevação da temperatura mínima, as taxas de acúmulo aumentaram, com maior valor absoluto de $140,9 \mathrm{~kg}$ MS ha ${ }^{-1} \mathrm{dia}^{-1}$.

As taxas de acúmulo em matéria seca obtidas no presente estudo superam aquelas obtidas por diversos autores: (i) Bryan \& Sharpe (1965) obtiveram 2,24 $\mathrm{kg} \mathrm{ha}^{-1} \mathrm{dia}^{-1}$ para o capim Pangola (Digitaria decumbens Stent); Singh \& Chatterjee (1968) reportaram taxas de 7,0; 5,4 e $1,1 \mathrm{~kg} \mathrm{ha}^{-1} \mathrm{dia}^{-1}$ para os capins Brachiaria brizantha, Andropogon gayanus e Paspalum notatum, respectivamente; Pedreira (1973), obteve, para o capim Colonião, taxas de 2,0; 3,6 e $8,7 \mathrm{~kg} \mathrm{ha}^{-1} \mathrm{dia}^{-1}$, nos meses de julho, agosto e setembro, respectivamente; enquanto Pedreira

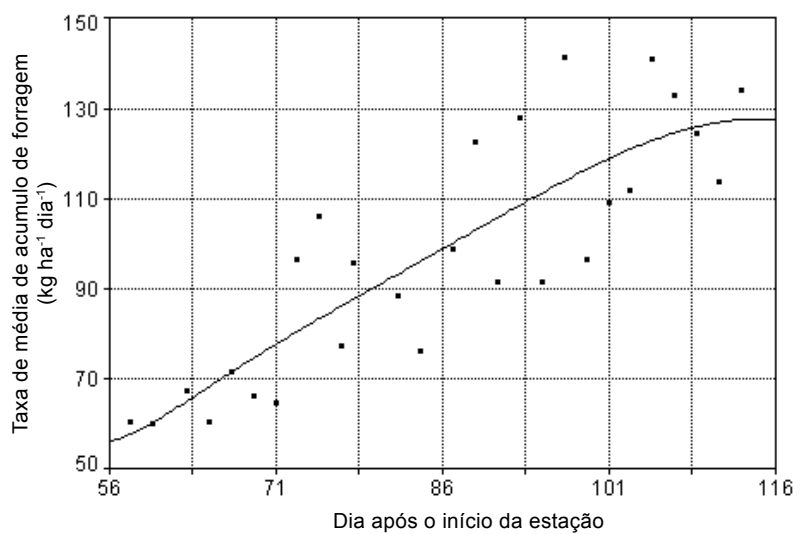

Figura 4 - Taxa média de acúmulo de forragem capim Mombaça, no período de primavera (Modelo 2)

(1979), ainda para o capim Colonião, reporta taxas de 1,$7 ; 7 ; 12,2 ; 22,3$ e $39,6 \mathrm{~kg} \mathrm{ha}^{-1} \mathrm{dia}^{-1}$, nos meses de agosto, setembro, outubro, novembro e dezembro, respectivamente.

A avaliação da influência de variáveis climáticas sobre a produção da pastagem exige bases comuns no que tange ao período de descanso. Para isso, foram consideradas somente as avaliações referentes ao período de descanso de 30 dias.

A análise de variância referente à massa de forragem após 30 dias de descanso, durante as avaliações, foi significativa devido as alterações climáticas (Tabela 2), permitindo a elaboração de modelos extrapoláveis para previsão da produção de Mombaça em função da lâmina de água diária (somatório da lâmina de água da irrigação e pluviosidade) e da temperatura mínima (Figura 5).

A produção de forragem apresentou relação positiva com o aumento dos níveis dessas variáveis e os modelos que melhor explicaram essas funções são 
Tabela 3 - Modelos para Panicum maximum cv. Mombaça com os respectivos valores do coeficiente de correlação (r), número de observações (n), desvio padrão (s) e valor $\mathrm{F}$.

\begin{tabular}{|c|c|c|c|c|c|}
\hline & 1 & 2 & 3 & 4 & 5 \\
\hline & \multicolumn{5}{|c|}{ Parâmetro do modelo } \\
\hline $\mathrm{A}$ & 14156,97 & $-1,57.10^{6}$ & 7261,66 & $-17561,89$ & 9502,57 \\
\hline B & $-6,70.10^{-4}$ & $-594,95$ & $7,9725.10^{-6}$ & 127467,00 & $-1021,25$ \\
\hline C & $-1,11.10^{6}$ & 33360,73 & $-16240,24$ & 646154,90 & 38,61 \\
\hline D & $3,12.10^{7}$ & $1,67.10^{7}$ & - & 911598,80 & 1536,83 \\
\hline$E$ & - & $-1,64.10^{7}$ & - & - & - \\
\hline f & - & - & - & - & 8,81 \\
\hline \multirow[t]{2}{*}{ g } & - & - & - & - & 0,34 \\
\hline & \multicolumn{5}{|c|}{ Parâmetro Estatístico } \\
\hline$r$ & 0,71 & 0,85 & 0,89 & 0,89 & 0,90 \\
\hline$n$ & 27 & 27 & 45 & 45 & 45 \\
\hline s & 792,47 & 26,39 & 1206,87 & 1206,87 & 1221,63 \\
\hline$f$ & $8,02^{* *}$ & $14,76^{* *}$ & $82,88^{* *}$ & $54,18^{* *}$ & 30,30 ** \\
\hline Modelo & \multicolumn{3}{|c|}{ Descrição } & \multicolumn{2}{|c|}{ Tipo } \\
\hline 1 & \multicolumn{3}{|c|}{$\begin{array}{l}\text { Massa de matéria seca }\left(\mathrm{kg} \mathrm{ha}^{-1}\right) \text {, na primavera, em função do } \\
\text { número de dias decorridos a partir do início do experimento (t, dias; } \\
t_{1}=58 ; t_{i}=113 \text { dias). }\end{array}$} & \multicolumn{2}{|c|}{$\begin{array}{c}M M S P=a+b t^{3}+\frac{c}{t}+\frac{d}{t^{2}} \\
\left(t_{1} \leq t \leq t_{i}\right)\end{array}$} \\
\hline
\end{tabular}

Taxa de acúmulo (TA, $\mathrm{kg} \mathrm{ha}^{-1} \mathrm{dia}^{-1}$ ), na primavera, em função do número de dias decorridos a partir do início do experimento (t, dias; $\mathrm{t}_{1}=58 ; \mathrm{t}_{\mathrm{i}}=113$ dias $)$.

$$
\begin{gathered}
T A=a+b t+c(\ln t)^{2}+\frac{d}{t^{0,5}}+e \frac{\ln t}{t} \\
\left(t_{1} \leq t \leq t_{i}\right)
\end{gathered}
$$

Modelo extrapolável referente à estimativa de massa de matéria

3 seca, aos 30 dias de crescimento (MMS30, $\mathrm{kg} \mathrm{ha}^{-1}$ ), em função da temperatura mínima $\left(\mathrm{Tm},{ }^{\circ} \mathrm{C}\right)$.

$$
M M S 30=a+b e^{T m}+\frac{c}{\sqrt{T m}}
$$$$
(12,62 \leq T m<19,30)
$$

4

Modelo extrapolável referente à estimativa da massa de matéria seca, aos 30 dias de crescimento (MMS30, $\mathrm{kg} \mathrm{ha}^{-1)}$, em função da lâmina de água diária ( $\left.\mathrm{Lw}, \mathrm{mm}^{\mathrm{dia}}{ }^{-1}\right)$.

Modelo extrapolável referente à estimativa da massa de matéria seca do Panicum maximum cv. Mombaça aos 30 dias de crescimento (MMS30, $\mathrm{kg} \mathrm{ha}^{-1}$ ), em função da temperatura mínima do $\operatorname{ar}\left(\mathrm{Tm},{ }^{\circ} \mathrm{C}\right)$ e da lâmina de água diária $\left(\mathrm{Lw}, \mathrm{mm} \mathrm{dia}^{-1}\right)$.

$$
M M S 30=a+b\left(\frac{\ln L w}{L w}\right)+\frac{c}{L w^{2}}+d e^{-L}
$$

$(3,25 \leq L w<10,04)$

${ }^{* *}$ Significativo a 1\%. Modelos 1,2: $\left(r_{26-0,01}=0,479\right)$; Modelos 3,4,5: $\left(r_{44-0,01}=0,377\right)$.
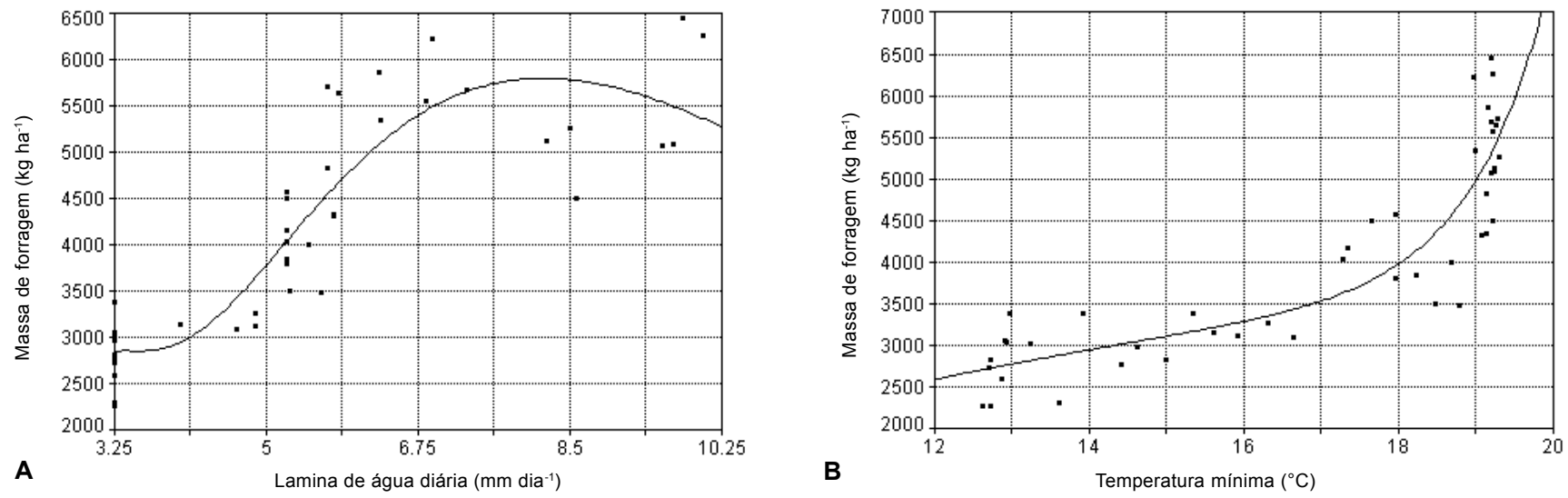

Figura 5 - Massa de forragem do capim Mombaça com período de descanso de 30 dias, em função das variáveis independentes: (a) lâmina de água diária (Modelo 4); (b) temperatura mínima (Modelo 3). 


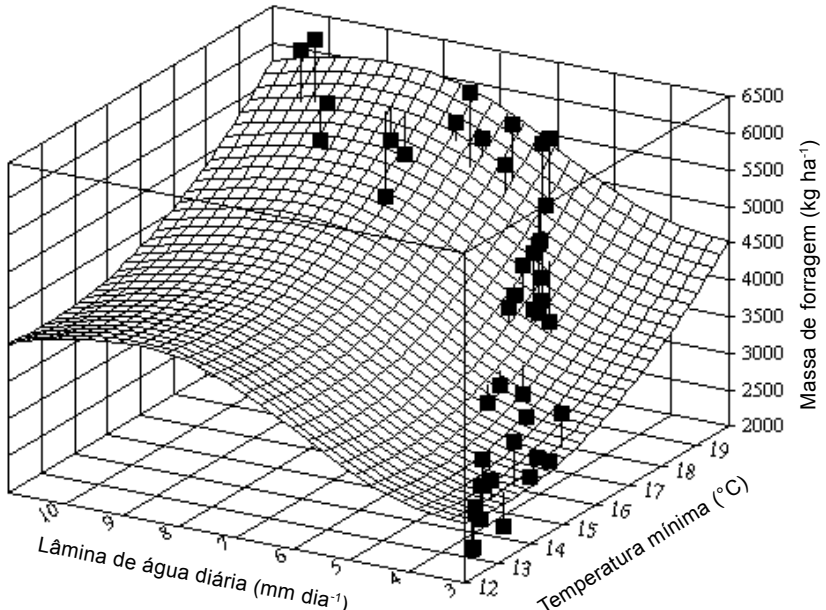

Figura 6 - Massa de forragem do capim Mombaça, com período de descanso de 30 dias, em função da temperatura mínima do ar e da lâmina de água diária (Modelo 5).

apresentados na Tabela 3 (Modelos 3 e 4). A partir desses resultados, foi elaborado novo modelo matemático extrapolável visando a previsão da produção de forragem do Mombaça em função da interação entre temperatura mínima e lâmina de água diária (Figura 6 e Tabela 3). A integração dessas variáveis tem por objetivo, assegurar maior precisão na previsão de rendimento do Mombaça, visto que, teoricamente, os modelos extrapoláveis devem considerar o maior número possível de variáveis independentes e a interferência dessas sobre a variável de interesse.

\section{CONCLUSÕES}

A produção de matéria seca de capim Mombaça, durante a primavera foi maior do que durante o inverno. Houve aumento da produção de matéria seca de capim Mombaça, com o aumento da temperatura mínima, bem como do período de descanso e da área foliar inicial.

Na região de cerrado, os principais atributos responsáveis pela produção de massa de forragem do capim Mombaça, foram temperatura mínima do ar e disponibilidade de água no solo.

\section{REFERÊNCIAS BIBLIOGRÁFICAS}

ALCÂNTARA, P.B.; BUFARAH, G. Plantas forrageiras: gramíneas e leguminosas. São Paulo: Livraria Nobel, 1985. 150p. (Biblioteca Rural)

BARBOSA, M.A.A.F.; DAMASCENO, J.C.; CECATO, U. Estudo de perfilhamento em quatro cultivares de Panicum maximum Jacq. submetidos a duas alturas de corte. In: REUNIÃO ANUAL DA SOCIEDADE BRASILEIRA DE ZOOTECNIA, 33., Fortaleza, 1996. Anais. Fortaleza: SBZ, 1996. v.2.
BRYAN, W.W.; SHARPE, J.P. The effect of urea nad cutting treatments on the production of Pangola grass in south-eastern Queensland. Australian Journal Experimental Agriculture Animal Husbandry, v.5, p.433-441, 1965.

BURKART, A. Evolution of Grasses and Grasslands in South America. Taxon V.24, p.53-66, 1975.

COOPER, J.P. Potential production and energy conversion in temperate and tropical grasses. Herbage Abstracts, v.40, p.1-15, 1970.

COOPER, J.P.; TAINTON, N.M. Light and temperature requirements for the growth of tropical and temperate grasses. Herbage Abstracts, v.38, p.167-176, 1968

GOMIDE, J.A. Fisiologia do crescimento livre de plantas forrageiras. In PEIXOTO, A.M. (Ed.) Pastagens: fundamentos de exploração racional. Piracicaba: FEALQ, 1994. p.1-14.

GOMIDE, J.A.; ZAGO, C.P. Produtividade do capim colonião (Panicum maximum), com e sem adubação de reposição, submetido a diferentes intervalos de corte. In: REUNIÃO ANUAL DA SOCIEDADE BRASILEIRA DE ZOOTECNIA, 18., Goiânia, 1981. Anais. Goiânia: SBZ, 1981.

JANDEL SCIENTIFIC. TableCurve 2D (software). Illinois, 1994.

JANK, L. Melhoramento e seleção de variedades de Panicum maximum. In: SIMPÓSIO SOBRE MANEJO DA PASTAGEM, 12., Piracicaba, 1995. Anais. Piracicaba: FEALQ, 1995. p.21-58.

JANK, L.; SAVIDAN, Y.H.; SOUZA, M.T.C.; COSTA, J.C.G. Avaliação do germolasma de Panicum maximum introduzida da Africa. I: Produção forrageira. Revista da Sociedade Brasileira de Zootecnia, v.23, p.433440, 1994

MALDONADO, H.; DAHER, F.R.; PEREIRA, A.V. Efeito da irrigação na produção de matéria seca do capim elefante (Pennisetum purpureum Schum) em Campos dos Goytacazes, RJ. In: REUNIÃO ANUAL DA SOCIEDADE BRASILEIRA DE ZOOTECNIA, 34., Juiz de Fora, 1997. Anais. Juiz de Fora: SBZ, 1997.

MCCLOUD, D.E. Temperature responses of some subtropical forage grasses. In: Conference of pastures and forages, São Paulo, 1963. Rome: FAO, 1963.

McWILLIAM, J.R. Response of pasture plants to temperature. In: WILSON, J.R. Plant relations in temperature. Australia: Commonwealth Scientific Industrial Research Organization, 1978. p.17-34.

MOTT, G.O. Measuring forage quantity and quality in grazing trials. In: SOUTHERN PASTURE AND FORAGE CROP IMPROVEMENT CONFERENCE, 37., Nashville, 1980. Proceedings. Nashville, 1980. p.39.

PEDREIRA, J.V.S. Crescimento estacional de capim pangola (Digitaria decumbens Stent.) e colonião (Panicum maximum Jacq.) na região de Barretos (SP). Zootecnia, v.17, p.215-223, 1979.

PEDREIRA, J.V.S. Crescimento estacional dos capins colonião Panicum maximum Jacq., gordura Melinis minutiflora Pal de Beauv, Jaraguá Hyparrhenia rufa (Ness) Stapf e pangola de Taiwan A-24 Digitaria pentzii Stent. Boletim da Indústria Animal, v.30, p.59-145, 1973.

PEREIRA, R.M.A.; SYKES, D.J.; GOMIDE, J.A.; VIDIGAL, G.T. Competição de 10 gramíneas para capineiras, no cerrado, em 1965. Revista Ceres v.13, p.141-153, 1966

ROLIM, F.A. Estacionalidade de produção de forrageiras. In: SIMPÓsIO SOBRE MANEJO DA PASTAGEM, 6., Piracicaba, 1980. Anais Piracicaba: FEALQ, 1980, p. 243-270.

SILVA, S.C. Condições edafo-climáticas para a produção de Panicum sp. In SIMPÓSIO SOBRE MANEJO DA PASTAGEM, 12., Piracicaba, 1995 Anais. Piracicaba: FEALQ, 1995. p.129-146.

SINGH, R.D.; CHATTERJEE, B.N. Growth analysis of perennial grasses in Tropical India. I: Herbage growth in pure grass swards. Experimental Agriculture, v.4, p.117-125, 1968.

SKERMAN, P.J.; RIVEROS, F. Poáceas tropicales. In: PRODUCCIÓN Y PROTECCIÓN VEGETAL, 23., Roma, 1992. Colección. Roma: FAO, 1992. 849p.

SOIL SURVEY STAFF. Agency for International Development. Soil Management Support Services. Keys to soil taxonomy. Washington: USDA, 1993. 422p.

WERNER, J.C. Adubação de pastagens de Brachiaria spp.. In: SIMPÓSIO SOBRE MANEJO DA PASTAGEM,11., Piracicaba, 1994. Anais. Piracicaba: FEALQ, 1994. p.202-209.

Recebido em 31.10.00 